@ERSpublications

Repeated multiple-breath washout tests should be twice the washout time apart to reduce avoidable measurement errors http://ow.ly/HPgW4

Elizabeth R. Salamon ${ }^{1}$, Kevin R. Gain ${ }^{1}$ and Graham L. Hall ${ }^{2,3}$

${ }^{1}$ Respiratory Medicine, Royal Perth Hospital, Perth, Australia. ${ }^{2}$ Respiratory Medicine, Princess Margaret Hospital for Children, Perth, Australia. ${ }^{3}$ Telethon Kids Institute, University of Western Australia, Perth, Australia.

Correspondence: Graham Hall, Paediatric Respiratory Physiology, Telethon Kids Institute, PO Box 855, West Perth, Western Australia 6872, Australia. E-mail: graham.hall@telethonkids.org.au

Received: Sept 022014 | Accepted after revision: Dec 242014 | First published online: Feb 052015

Support statement: G.L. Hall is funded by an Australian National Health and Medical Research Council Fellowship (grant APP1025550). Funding information for this article has been deposited with FundRef.

Conflict of interest: None declared.

Acknowledgements: This work was presented at the 2010 European Respiratory Society Annual Congress in Barcelona, Spain, as an oral presentation. The authors would like to acknowledge the participants of this study from Princess Margaret Hospital and Royal Perth Hospital (Perth, Australia). They would also like to acknowledge statistician Michael Phillips from the Medical Research Foundation at Royal Perth Hospital for providing statistical analysis.

\title{
References
}

1 Pellegrino R, Viegi G, Brusasco V, et al. Interpretative strategies for lung function tests. Eur Respir J 2005; 26 : 948-968.

2 Wanger J, Clausen JL, Coates A, et al. Standardisation of the measurement of lung volumes. Eur Respir J 2005; 26 : 511-522.

3 Blonshine S, Foss C, Mottram C, et al. AARC clinical practice guideline: body plethysmography: 2001 revision and update. Respir Care 2001; 46: 506-513.

4 Newth CJ, Enright P, Johnson RL. Multiple-breath nitrogen washout techniques: including measurements with patients on ventilators. Eur Respir J 1997; 10: 2174-2185.

5 Miller MR, Hankinson J, Brusasco V, et al. Standardisation of spirometry. Eur Respir J 2005; 26: 319-338.

6 Hall GL, Thompson BR, Stanojevic S, et al. The Global Lung Initiative 2012 reference values reflect contemporary Australasian spirometry. Respirology 2012; 17: 1150-1151.

7 Quanjer PH, Stanojevic S, Cole TJ, et al. Multi-ethnic reference values for spirometry for the 3-95-yr age range: the Global Lung Function 2012 equations. Eur Respir J 2012; 40: 1324-1343.

8 Cook CD, Hamann JF. Relation of lung volumes to height in healthy persons between the ages of 5 and 38 years. J Pediatr 1961; 59: 710-714

9 Crapo RO, Morris AH, Clayton PD, et al. Lung volumes in healthy nonsmoking adults. Bull Eur Physiopathol Respir 1982; 18: 419-425.

10 Robinson PD, Latzin P, Verbanck S, et al. Consensus statement for inert gas washout measurement using multiple- and single-breath tests. Eur Respir J 2013; 41: 507-522.

11 Morris MG, Gustafsson P, Tepper R, et al. The bias flow nitrogen washout technique for measuring the functional residual capacity in infants. Eur Respir J 2001; 17: 529-536.

\section{Dual gas techniques for peripheral airway function: diffusing the issues}

To the Editor:

In the quest to investigate small airway function in a range of lung diseases, multiple-breath washout tests have been applied for their potential to represent the most peripheral air spaces $[1,2]$. The aim of reducing the burden on the patient has recently also revived interest in the single-breath washout. A single-breath washout test has now been proposed which involves an inhalation of $5 \% \mathrm{SF}_{6}, 26.3 \% \mathrm{He}, 21 \%$ $\mathrm{O}_{2}$ and the balance as $\mathrm{N}_{2}$ in order to obtain a so-called dual gas tracer (DTG) phase III slope [3]. After having been introduced as a practical and promising lung function tool [3] and as an early detection tool in cystic fibrosis lung disease [4], the DTG phase III slope is now advocated as a specific index of acinar function abnormality in children with mild asthma [5]. An editorial in the European Respiratory Journal [6], reflecting upon a DTG reproducibility study in normal subjects and chronic obstructive pulmonary 
disease (COPD) patients [7], rightly pointed out that the clinical utility of DTG indices will depend on their actual physiological meaning. We provide here a critical appraisal of the physiological meaning of the DTG phase III slope.

Why use two gases, such as $\mathrm{He}$ and $\mathrm{SF}_{6}$, at all? Because the He diffusion front is located a few generations proximal to the $\mathrm{SF}_{6}$ diffusion front [8], and the $\mathrm{He}$ and $\mathrm{SF}_{6}$ phase III slopes are thought to represent airway function in the proximal and peripheral part of the acinus, respectively. Ventilation heterogeneities generated in the conductive airways are expected to affect the $\mathrm{He}$ and $\mathrm{SF}_{6}$ phase III slopes to the same extent. Hence, the difference between $\mathrm{He}$ phase III slope and $\mathrm{SF}_{6}$ phase III slope $\left(\mathrm{SF}_{6}-\mathrm{He}\right.$ phase III slope difference) has been used as an indicator of intra-acinar function. Even if lung geometry were to change dramatically so as to push the $\mathrm{He}$ and $\mathrm{SF}_{6}$ diffusion fronts out of, or further into the acinus, similar principles would apply, with $\mathrm{SF}_{6}$ representing more peripheral structures than He. The $\mathrm{SF}_{6}-\mathrm{He}$ phase III slope difference has been used as an indicator of peripheral lung disease: it has been correlated to histomorphometry of airways in the smoker's lungs [9], indicated peripheral changes in asthmatics [10], detected a specific peripheral response to methacholine in lung transplant recipients [11], and suggested peripheral sites of allergic reaction [12]. One pitfall when interpreting dual gas washout tests is that an absence of change in $\mathrm{SF}_{6}-\mathrm{He}$ phase III slope difference cannot exclude an intra-acinar effect, for instance when both proximal and peripheral acinar structures affect $\mathrm{He}$ and $\mathrm{SF}_{6}$ phase III slopes to the same extent. By contrast, however, a change in $\mathrm{SF}_{6}-\mathrm{He}$ phase III slope difference definitely signals an intra-acinar effect.

The interpretation problem with the DTG phase III slope lays much closer to the way it is determined: derived from the molar mass (MM) signal, the DTG signal is generally referred to as an "aggregate" measure of $\mathrm{He}$ and $\mathrm{SF}_{6}$. Yet it is assumed that the DTG phase III slope somehow also differentiates between He and $\mathrm{SF}_{6}$ diffusive transport in the lungs, and that ternary diffusion (between $\mathrm{He}, \mathrm{SF}_{6}$ and $\mathrm{N}_{2}$ ) can be neglected. Also, as pointed out in the editorial [6], the confounding effect of, for instance, the partial $\mathrm{N}_{2}$ washout on the DTG curve is not understood. In an attempt to better understand the potential of the DTG curve, we first considered a set of physiologically plausible $\mathrm{He}, \mathrm{SF}_{6}, \mathrm{O}_{2}, \mathrm{CO}_{2}$ and $\mathrm{N}_{2}$ traces as a function of exhaled volume during a DTG experiment (fig. 1a). Besides considering dilution of the various inhaled gas components $\left(26.3 \% \mathrm{He}, 5 \% \mathrm{SF}_{6}, 21 \% \mathrm{O}_{2}\right.$ and $47.7 \% \mathrm{~N}_{2}$ ), we imposed the following physiological constraints (based on published experimental data for normal subjects $[8,13-15])$ : Fowler dead space for He and $\mathrm{SF}_{6}$ was considered to differ by $40 \mathrm{~mL}[13,14]$; He and $\mathrm{SF}_{6}$ normalised phase III slopes were set to 0.07 and $0.13 \mathrm{~L}^{-1}$, respectively $[8,13,14]$; at mid-expiration, $\mathrm{CO}_{2}$ and $\mathrm{O}_{2}$ concentrations were set to 4 and $17 \%$, respectively, and their phase III slopes were considered to be opposite but equal in magnitude $[3,15]$. Finally, $\mathrm{N}_{2}$ concentration traces were obtained by mass balance at each instance during the expiration. Using 146, 44, 32, 28 and $4 \mathrm{~g} \cdot \mathrm{mol}^{-1}$ for SF$_{6}$, $\mathrm{CO}_{2}, \mathrm{O}_{2}, \mathrm{~N}_{2}$ and $\mathrm{He}$, respectively, we then derived the corresponding $\mathrm{MM}$ signal and removed an offset based on the MM signal for air breathing, as previously described [3,7], to obtain $\mathrm{MM}\left(\mathrm{He}, \mathrm{SF}_{6}\right)$ or the so-called DTG curve. From this curve, the DTG peak $\left(0.6 \mathrm{~g} \cdot \mathrm{mol}^{-1}\right)$ and DTG phase III slope $\left(-0.2 \mathrm{~g} \cdot \mathrm{mol}^{-1} \cdot \mathrm{L}^{-1}\right.$ between 0.6 and $0.9 \mathrm{~L}$ expired volume) correspond to that obtained by HusEMANN et al. [7] in their normal group. Basically, this approach consists of considering a set of internally consistent $\mathrm{He}, \mathrm{SF}_{6}, \mathrm{O}_{2}, \mathrm{CO}_{2}, \mathrm{~N}_{2}$ traces, and calculating the $\mathrm{MM}\left(\mathrm{He}, \mathrm{SF}_{6}\right)$ curve as its mathematical consequence.

We now apply this same approach to two potential scenarios of lung disease: 1) He and $\mathrm{SF}_{6}$ phase III slope are increased by a same amount, leaving the $\mathrm{SF}_{6}-\mathrm{He}$ phase III slope difference unaltered at $0.06 \mathrm{~L}^{-1}$ (fig. 1b); or 2) both $\mathrm{He}$ and $\mathrm{SF}_{6}$ phase III slopes are increased proportionally, resulting in an increased $\mathrm{SF}_{6}-\mathrm{He}$ phase III slope difference (fig. 1c). In both hypothetical disease states, the average of the He and $\mathrm{SF}_{6}$ phase III slope is five-fold that of the normal case $\left(0.5\right.$ versus $\left.0.1 \mathrm{~L}^{-1}\right)$. Let us now observe the corresponding behaviour of the DTG curve and its phase III slope. Scenario 1, where the He and $\mathrm{SF}_{6}$ phase III slopes increase to the same extent (by $0.4 \mathrm{~L}^{-1}$ ), can be representative of either a conductive airway change (e.g. bronchoprovocation) or an intra-acinar change coincidently affecting $\mathrm{He}$ and $\mathrm{SF}_{6}$ by the same fixed amount. As expected in this case, the $\mathrm{SF}_{6}-\mathrm{He}$ phase III slope difference is unaffected, yet the DTG phase III slope does change (in this particular case, it becomes zero). Scenario 2, where the He and $\mathrm{SF}_{6}$ phase III slopes show the same relative increase (by a factor of five), both the $\mathrm{SF}_{6}-\mathrm{He}$ phase III slope difference and the DTG phase III slope increase in absolute value, probably due to an acinar effect. In fact, the DTG curve obtained with scenario 2 probably represents a typical COPD patient in [7], even if a rigorous approach should include perfusion inequality (affecting $\mathrm{O}_{2}$ and $\mathrm{CO}_{2}$ curves). However, in a first approximation, DTG phase III slope in COPD patients with low diffusing capacity [7] probably relates to the acinar defect. It is in other disease states that extreme caution is warranted when propagating DTG phase III slope as an indicator of acinar change. Otherwise, some patients with a modified DTG phase III slope, e.g. in a state of bronchoprovocation leading to scenario 1, might get treated for peripheral lung defects that are simply not there. 

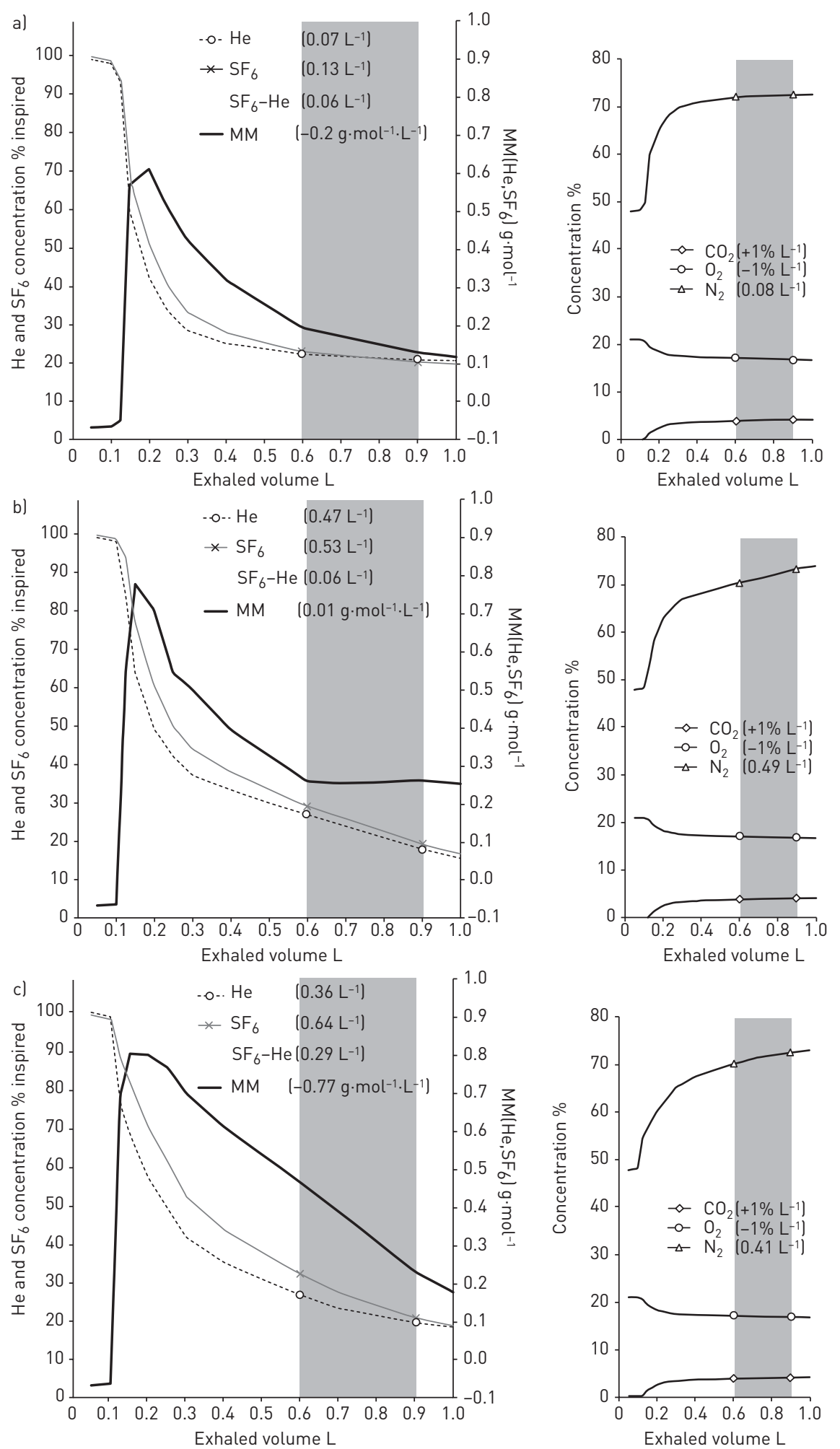

FIGURE 1 Expired concentration traces of gases involved $\left(\mathrm{He}, \mathrm{SF}_{6}, \mathrm{CO}_{2}, \mathrm{O}_{2}\right.$ and $\left.\mathrm{N}_{2}\right)$ when considering a $1 \mathrm{~L}$ inspiration of the dual gas mixture in an air-filled $3 \mathrm{~L}$ lung volume, and the corresponding so-called dual tracer gas (DTG) curve based on molar mass $\left(\mathrm{MM}\left(\mathrm{He}, \mathrm{SF}_{6}\right)\right)$; see the text for computational details. Also indicated are the phase III slopes computed between 0.6 and $0.9 \mathrm{~L}$ of expired volume (grey area) for all gases; for ease of assessing compatibility with phase III slope values in the literature, $\mathrm{He}$ and $\mathrm{SF}_{6}$ phase III slopes are divided by the inspired minus the mean expired $\mathrm{He}$ or $\mathrm{SF}_{6}$ concentration; $\mathrm{N}_{2}$ phase III slope is divided by the mean expired minus the inspired $\mathrm{N}_{2}$ concentration; $\mathrm{MM}\left(\mathrm{He}, \mathrm{SF}_{6}\right), \mathrm{O}_{2}$ and $\mathrm{CO}_{2}$ phase III slopes are not normalised. Three cases are considered: a) a normal lung; b) a diseased lung showing increased $\mathrm{He}$ and $\mathrm{SF}_{6}$ phase III slopes with $\mathrm{SF}_{6}-\mathrm{He}$ phase III slope difference unaffected; or c) with $\mathrm{SF}_{6}-\mathrm{He}$ phase III slope difference increased. 
The intrinsic problem with using an aggregate $\mathrm{MM}\left(\mathrm{He}, \mathrm{SF}_{6}\right)$ signal to derive a DTG phase III slope as an index of acinar ventilation heterogeneity, also points to a possible solution. The $\mathrm{O}_{2}$ and $\mathrm{CO}_{2}$ traces, which are measured independently, can be inspected for variations in respiratory quotient. They can also be converted into their combined molar mass, to then extract a $\mathrm{N}_{2}$ concentration curve. Then, the ensemble of DTG curves can be inspected in order to determine whether a particular patient phenotype is compatible with a scenario of type 1 or 2 , or another alternative. We conclude that the noninvasive DTG test does hold promise for clinical use, but inevitably the patient's ease of performing the test is inversely related to the physician's effort to extract physiological meaning from it.

0 @ERSpublications

Peripheral ventilation heterogeneity can be extracted from the dual gas test by considering all its gas components http://ow.ly/I62C8

Sylvia Verbanck ${ }^{1}$ and Manuel Paiva ${ }^{2}$

${ }^{1}$ Respiratory Division, University Hospital UZ Brussel, Brussels, Belgium. ${ }^{2}$ Respiratory Division, University Hospital Erasme, Université Libre de Bruxelles, Brussels, Belgium.

Correspondence: Sylvia Verbanck, Respiratory Division, University Hospital UZ Brussel, Laarbeeklaan 101, 1090 Brussels, Belgium. E-mail: sylvia.verbanck@uzbrussel.be

Received: Nov 072014 | Accepted after revision: Dec 242014 | First published online: March 052015

Conflict of interest: None declared.

\section{References}

Verbanck S, Paiva M. Gas mixing in the airways and airspaces. Compr Physiol 2011; 1: 809-834.

2 Robinson PD, Latzin P, Verbanck S, et al. Consensus statement for inert gas washout measurement using multiple- and single- breath tests. Eur Respir J 2013; 41: 507-522.

3 Singer F, Stern G, Thamrin C, et al. Tidal volume single breath washout of two tracer gases - a practical and promising lung function test. PLoS One 2011; 6: e17588.

4 Singer F, Stern G, Thamrin C, et al. A new double-tracer gas single-breath washout to assess early cystic fibrosis lung disease. Eur Respir J 2013; 41: 339-345.

5 Singer F, Abbas C, Yammine S, et al. Abnormal small airways function in children with mild asthma. Chest 2014; 145: 492-499.

6 Latzin P, Thompson B. Double tracer gas single-breath washout: promising for clinics or just a toy for research? Eur Respir J 2014; 44: 1113-1115.

7 Husemann K, Berg N, Engel J, et al. Double tracer gas single-breath washout: reproducibility in healthy subjects and COPD. Eur Respir J 2014; 44: 1210-1222.

8 Dutrieue B, Vanholsbeeck F, Verbanck S, et al. A human acinar structure for simulation of realistic alveolar plateau slopes. J Appl Physiol 2000; 89: 1859-1867.

9 Van Muylem A, De Vuyst P, Yernault JC, et al. Inert gas single-breath washout and structural alteration of respiratory bronchioles. Am Rev Respir Dis 1992; 146: 1167-1172.

10 Gustafsson PM, Ljungberg HK, Kjellman B. Peripheral airway involvement in asthma assessed by single-breath $\mathrm{SF}_{6}$ and He washout. Eur Respir J 2003; 21: 1033-1039.

11 Van Muylem A, Paiva M, Estenne M. Involvement of peripheral airways during methacholine-induced bronchoconstriction after lung transplantation. Am J Respir Crit Care Med 2001; 164: 1200-1203.

12 Haccuria A, Michils A, Michiels S, et al. Exhaled nitric oxide: a biomarker integrating both lung function and airway inflammation changes. J Allergy Clin Immunol 2014; 134: 554-559.

13 Lacquet LM, van Muylem A. He and $\mathrm{SF}_{6}$ single-breath expiration curves. Comparison with the paiva-engel model. Bull Eur Physiopathol Respir 1982; 18: 239-246.

14 Paiva M, van Muylem A, Ravez P, et al. Inspired volume dependence of the slope of the alveolar plateau. Respir Physiol 1984; 56: 309-325.

15 Cormier Y, Bélanger J. Quantification of the effect of gas exchange on the slope of phase III. Bull Eur Physiopathol Respir 1983; 19: 13-16. 